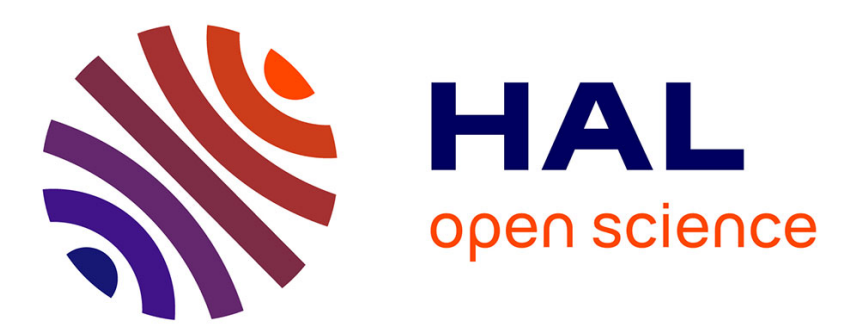

\title{
Far from equilibrium crystalline to amorphous phase transition induced by mechanical alloying in the Fe-Si system
}

\author{
M. Abdellaoui, T. Barradi, E. Gaffet
}

\section{- To cite this version:}

M. Abdellaoui, T. Barradi, E. Gaffet. Far from equilibrium crystalline to amorphous phase transition induced by mechanical alloying in the Fe-Si system. Journal de Physique IV Proceedings, 1992, 02 (C3), pp.C3-73-C3-78. 10.1051/jp4:1992310 . jpa-00251515

HAL Id: jpa-00251515 https://hal.science/jpa-00251515

Submitted on 1 Jan 1992

HAL is a multi-disciplinary open access archive for the deposit and dissemination of scientific research documents, whether they are published or not. The documents may come from teaching and research institutions in France or abroad, or from public or private research centers.
L'archive ouverte pluridisciplinaire $\mathbf{H A L}$, est destinée au dépôt et à la diffusion de documents scientifiques de niveau recherche, publiés ou non, émanant des établissements d'enseignement et de recherche français ou étrangers, des laboratoires publics ou privés. 


\title{
Far from equilibrium crystalline to amorphous phase transition induced by mechanical alloying in the Fe-Si system
}

\author{
M. ABDELLAOUI, T. BARRADI* and E. GAFFET
}

CECM, CNRS, 15 Rue G. Urbain, 94407 Vitry-sur-Seine cedex, France

'SUPELEC, 91192 Gif-sur-Yvette cedex, France

\begin{abstract}
Starting from a mixture of $\mathrm{Fe}$ and $\mathrm{Si}$ powders, the mechanical alloying leads to an expansion (up to $16 \% \mathrm{Si}$ - in wt) of the $\mathrm{A2}$ phase domain $[1,8]$. In this composition field, we report on the influence of the structural state and the grain size on the coercive force and the microhardness. By Vicker's microhardness measurements, the expansion of the A2 phase domain up to $15 \mathrm{wt} \%-\mathrm{Si}$ is confirmed. The starting of the ordering reaction A2 to $\mathrm{B} 2$ phase is above $16 \mathrm{wt} \%-\mathrm{Si}$ and the existence of the D03 phase is at 17 wt \%-Si. A high coercive force for the $5 \mathrm{wt} \%$ sample has been reported.
\end{abstract}

\section{INTRODUCTION}

Since adding silicon to electrical steels has become common because silicon increases the resistivity with a subsequent reduction in magnetic losses, the magnetic properties of the Fe-Si alloys were the subject of study of many authors. These magnetic properties such as coercive force, power losses, permeability and saturation magnetization were found to be strongly influenced by the structural state, the grain size, the magnetic domain structure and the lattice microdistortions. Narita et al. [2] studied the magnetic properties of a $\mathrm{Fe}+\mathrm{Si} 6.5 \mathrm{wt} \%$ alloy and concluded that the D03 ordered structure was more effective in improving the magnetic properties than the B2 ordered phase. More recently, Degauque et al. [3] concluded that losses were lower in the $\mathrm{Fe}+\mathrm{Si} 6.5 \mathrm{wt} \%$ ribbons ( which involved $\mathrm{B} 2$ ordered phase) than in those involving $\mathrm{D03}$ ordered structure. To explain the origin of this difference, M.V.P Altoé et al. [4] studied the effect of aging treatments in the temperature range $400-700^{\circ} \mathrm{C}$ on the microstructure and the magnetic properties of Fe-6.4 wt\%Si. The authors concluded that : the existence of 1/4[111] antiphase boundaries of B2 showing a marked anisotropy induces a deterioration of the magnetic properties since they lead to a reduced mobility for the magnetic domain walls whereas large grain size and more isotropic B2 antiphase boundaries seem to be promising. The effect of magnetic domain structures and grain size on the coercive force has been reported by M.A.Cunha et al. [5] which studied by lorentz microscopy the $\mathrm{Fe}+\mathrm{Si} 6.06$ wt\% magnetic domain structures. The authors concluded that a complexe domain structure is formed in small grain size specimens resulting in a relatively high coercivity materials whereas large grain size specimens 
have an anti-parallel domain structure resulting in low coercivity and low core loss material. The plastic deformation effects on the magnetic properties were reported by N. A. Dvorovenko et al. [6] for a Fe+1.5 wt\%-Si alloy. The authors concluded that the coercive force and the microhardness were governed by the level of lattice microdistortion; in fact they suggest that dislocations are insurmountable obstacles for the domain walls and form the level of the coercive force of the material. The microhardness of the $\mathrm{Fe}-\mathrm{Si}$ alloys, which is a primordial condition for the alloy rolling, is a function of the structural state. In fact F. Faudot et al. [7] show that the D03 phase hardens the material whereas the B2 phase softens it. The purpose of this work is to study the phase transitions induced by mechanical alloying in the Fe-Si system, the formation mechanism of the A2 solid solution (up to 16\%wt - in $\mathrm{Si}$ ) and finally the influence of the grain size and the structural state of the as milled powder on the coercive force and the microhardness in the 0 up to 16 wt\%-Si composition range.

\section{EXPERIMENTAL PROCEDURES}

a) Mechanical Alloying Conditions : The mechanical alloying was carried out using a classical P5/2(10) Fristch planetary high energy ball - milling machine. The rotation speed of the vials and the disc were respectively 765 and $340 \mathrm{rpm}$. The MA process duration was fixed to 168 hours. $10 \mathrm{~g}$ of a mixture of pure Fe powder (pro labo , R. P. Normapur) and of pure Si (hyperpure polycristalline silicon) pieces were introduced into a cylindrical tempered steel container of capacity $45 \mathrm{ml}$. Each container was loaded with five balls (diameter $1.5 \mathrm{~cm}$; mass $14 \mathrm{~g}$ ). The milling was proceeded in a stationary argon atmosphere.

\section{RESULTS AND DISCUSSION}

a) End Product Structural State : Structural state study is carried on by XRD pattern investigations carried out using a $(\theta-2 \theta)$ Philips diffractometer with the Co $\mathrm{K}_{\alpha}$ radiation ( $\lambda=0.17889 \mathrm{~nm}$ ). Based on these XRD pattern investigations in the zero up to $16 \mathrm{wt} \%$-Si composition range, the A2 c.c disordered solid solution phase and an amorphous phase at the same content in silicon were detected (no amorphous phase for the as milled compositions from pure iron up to $2 \mathrm{wt} \% \mathrm{Si}$ content). According to the equilibrium Fe-Si phase diagram, the A2 phase domain has been considerably enlarged (the equilibrium value is $4.25 \mathrm{wt} \%$ ). For Si content larger than $16 \mathrm{wt} \%$, the phases induced by mechanical alloying were reported in our previous works $[1,8]$.

b) Phase Transition Mechanism : based on XRD pattern investigations for samples milled for 12,24 and 168 hours, it was shown $[1,8]$ that : the Si content in the crystalline A2 phase increases as the MA process evolves; the milling process induces a crystalline lattice parameter expansion as a comparison with the corresponding equilibrium A2 phase (Fig 1) ; the grain size and the lattice parameter decrease as a function of the milling duration. Such a grain size decreasing induces a lattice parameter expansion which leads to the crystalline structure destabilization and to the amorphous phase formation. 
c) Microhardness as a Function of the Structural State : The microhardness measurements were carried out using a"Durimet" microhardness apparatus. In order to study the microhardness dependence on the structural state, the samples were annealed during 24 hours at $500^{\circ} \mathrm{C}$. Fig 2 exhibits the mic-

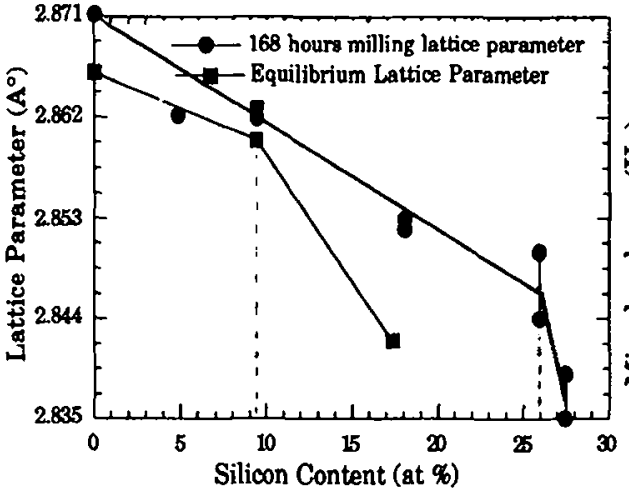

Fig. 1 : Lattice parameter as a function of the Si content

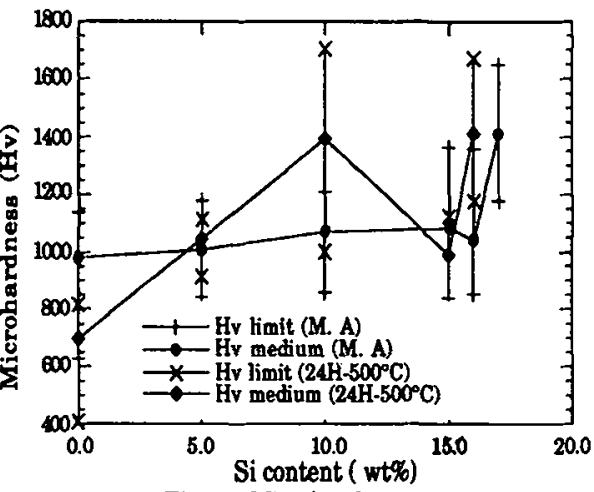

Fig. 2 : Microhardness as a function of the Si content

rohardness variation versus the $\mathrm{Si}$ content. The above mentioned figure shows that the as milled powder microhardness grows slightly until 15 wt\%$\mathrm{Si}$ but considering the measurement errors it is assumed that the microhardness value remains constant up to $15 \mathrm{wt} \%-\mathrm{Si}$, decreases slightly for $16 \mathrm{wt} \%-\mathrm{Si}$ and then increases strongly for $17 \mathrm{wt} \%-\mathrm{Si}$. Since the $\mathrm{B2}$ ordered phase softens the material whereas the D03 phase hardens it [7], we assume that the microharness is governed by the A2 phase state until $15 \mathrm{wt} \%$. Such microhardness values which were found to be constant give explanation of the A2 phase domain expansion. The decrease of the microhardness value in the vicinity of the $16 \mathrm{wt} \%-\mathrm{Si}$ composition involves the existence of a slight amount of the B2 phase which softens the material. Since the intensity of X-ray (100) superlattice line, characteristic of the B2 phase, is very weak as compared with the A2 (110) X-ray line intensity, the evidence of $\mathrm{B} 2$ phase existence is not allowed by the $\mathrm{X}$-ray characterization. The microhardness increases strongly for $17 \mathrm{wt} \%$, this fact is related to the presence of the $\mathrm{D} 03$ phase which hardens the material. The XRD investigations after annealing treatments involved the existence of a single A2 phase in pure iron and $5 \mathrm{wt} \%$-Si composition samples, the existence of a mixture of A2, B2 and D03 phases in the $10 \mathrm{wt} \%-\mathrm{Si}$ composition sample, the existence of a mixture of $\mathrm{B} 2$ and $\mathrm{D} 03$ phases in the $15 \mathrm{wt} \%-\mathrm{Si}$ composition sample and finally the existence of only the $\mathrm{D} 03$ phase in the $16 \mathrm{wt} \%$-Si composition sample. Based on these XRD investigations, we assume that, after annealing, the increase of the microhardness until $10 \mathrm{wt} \%$ is attributed to the existence of the A2 phase and to the growth of the D03 phase which hardens enough the material as the sample composition go near to the vicinity of $10 \mathrm{wt} \%$. The growth of the $\mathrm{B2}$ phase leads to a decrease of the microhardness which reaches its minimum at $15 \mathrm{wt} \%(989 \mathrm{Hv})$. Then the 
microhardness strongly increases up to $16 \mathrm{wt} \%$ composition for which only the D03 phase exists. The microhardness values in our work were found to be slightly larger than the [7] ones. Such an increase of the microhardness is related to the lattice microdistortions induced by dislocations created during the deformation of the material. This fact has been previously reported by [6].

\section{d) Magnetic Characterization}

* - Curie temperature as a function of the Si content : A thermomagnetogravimeter (TMG) was used for the curie temperature determination. Based on these TMG investigations, we observe that in the 0 up to $16 \mathrm{wt} \%$ - Si composition range ( pure iron not included), the TMG responses obtained after cooling down the samples reveal the reversibility of the thermomagnetic behaviour. Taking in account the fact that the amorphous crystallization temperature was lower than the magnetic transition one [1], one may propose that the samples start to crystallise before the thermal cancellation of the magnetisation is reached, and this obscure the measurement of the amorphous curie temperature in the just mentioned composition field. As it has been observed that the Ms value decreases either with increasing density of the grain boundary or with decreasing the microcrystallite size [10], one may propose that the two steps magnetic transition in the as milled pure iron is related to the existence of two different grain size phases. In the 17 up to 40 wt\%-Si composition range the TMG heating curie temperature was different from the cooling one. Fig. 3 exhibits the curie temperature as a function of the Si content. The DSC heating curie temperatures were similar to those reported by J.Talbot [11] whereas the TMG heating and the TMG cooling curie temperatures, for the composition range 17 up to $40 \mathrm{wt} \%-\mathrm{Si}$, were lower. It is worth noting that a second TMG heating followed by a cooling, for the just above mentioned composition range, increases the curie temperature. This fact is related to the decrease of the density of grain boundaries and the increase of the grain size when the samples were submitted to several heating runs.

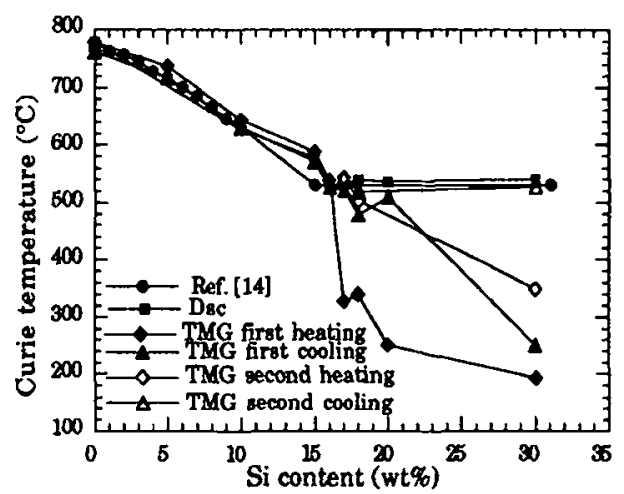

Fig. 3 : Curie temperature as a function of the Si content 
** - Coercive Force as a function of the Si content : The coercive force measurements were carried out at $1.5 \mathrm{kHz}$ frequency using a hysteresigraph apparatus. The coercive force variation versus Si content (Fig. 5) is not monotonic but it is synchron with the lattice microdistortions illustrated by the grain size distribution (Fig. 4). In fact, the Hc value strongly increases at $5 \mathrm{wt} \%$. For this content it reaches its maximum and then decreases to almost the same level as the pure iron value. In the 10 up to 16 wt \% composition range, we note a slight variation of the Hc value. The lattice microdistorsion value variations show the same behaviours; it reaches its maximum at $5 \mathrm{wt} \%$ (75\% of grains have a small size (Fig. 4)) then it decreases to the same value with a slight variation for all the compositions. We suggest that the Hc increases when increasing the lattice microdistortion as a result of decreasing grain size. This is what it has been reported by $[4,7,6]$.

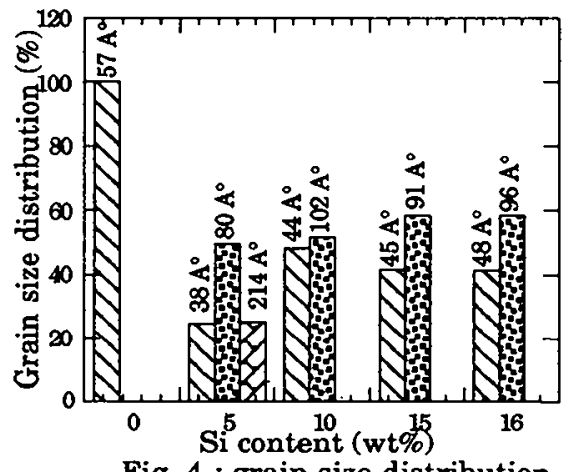

Fig. 4 : grain size distribution as a function of the Si content

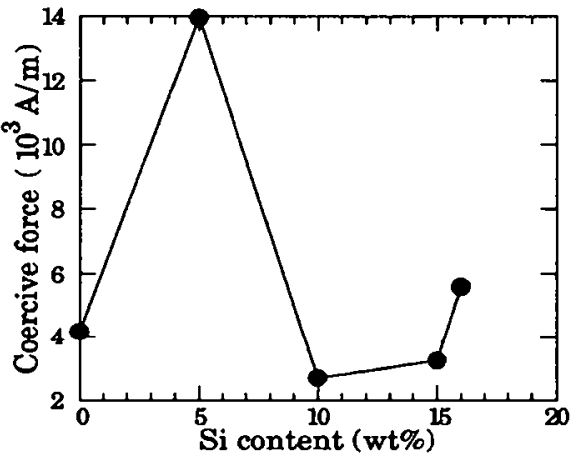

Fig 5 : coercive force as a function of the Si content

\section{CONCLUSION}

Based on XRD pattern investigations and microhardness measurements, an expansion of the A2 phase domain up to $15 \mathrm{wt} \%$, a starting of the ordering reaction $\mathrm{A} 2$ to $\mathrm{B} 2$ order phase at $16 \mathrm{wt} \%$, an amorphous and nanocrystalline phases were detected. The influence of the amorphous crystallisation temperature on the curie one was also studied. The coercive force was found to be strongly coupled with the lattice microdistortions and the grain size; it exhibits a maximum value for the 5 wt\%-Si composition sample.

Acknowledgements : The authors thank Dr. M. Harmelin (DSC) and Dr. F. Faudot (DTA) for fruitful help. 


\section{References :}

[1] M. Abdellaoui, F. Faudot, E. Gaffet - le vide, les couches minces-supplement au N²61 Mars-Avril 1992, 161-163

[2] K. Narita and M. Enokisono - IEEE Trans. Magn. Mag 15, 911(1979)

[3] J. Degauque, D. Bouchara \& all. - IEEE Trans. Magn. Mag-26, 2220 (1990)

[4] M. V. P. Altoé, M. S. Lancarotte \& all. - IEEE Trans. Magn, Vol. 27, NO. 6 (1991)

[5] M. A. Cunha and G. W. Johnson - J. Mat. Sci. Vol. 26 (1991) 5717-5724

[6] N. A. Dvorovenko, S. A. Zhernov \& all. - Phys. Met. Metall. Vol. 71, NO. 5, 181-186, 1991

[7] F. Faudot, J. F. Riallandand J. Bigot - Physica. Scripta. Vol. 39, 263-267, 1989

[8] E. Gaffet, N. Malhouroux, M. Abdellaoui - J. of Alloys and compounds, (Accepted)

[9] M. J. Tenwick, H. A. Davies - J. rapid solidif. 1984 - 85, Vol. 1, 143 - 155

[10] E. Hellstern and L. Schultz - J. Appl. Phy.,63 (5), 1 march 1988

[12] J. Talbot - Nouveau traité de chimie minérale tome XX, 1983 - 1994 